\title{
Research of Case Teaching Practice in C\# Programming Language
}

\author{
Benting Wan \\ School of Software and Internet of Things Engineering \\ Jiangxi University of Finance and Economics \\ Nanchang, China
}

\author{
Yue Liu \\ School of Software and Internet of Things Engineering \\ Jiangxi University of Finance and Economics \\ Nanchang, China
}

\begin{abstract}
In order to improve students' ability to analyze and solve problems, this paper designs and implements the $C \#$ programming language case teaching practice course, which is aimed at senior undergraduate computer majors. The design of the basic case and the comprehensive case and the process of case implementation are elaborated in detail, and the teaching effect is analyzed through recent cases. The comparison of case teaching shows that the case teaching of $\mathrm{C \#}$ programming language can not only improve students' ability to analyze problems and solve problems, but also greatly improve students' comprehensive application ability.
\end{abstract}

Keywords-Case Teaching;C\# programming language; Comprehensive ability

\section{INTRODUCTION}

The application of Case Teaching began at Harvard Law School and has been widely used in the teaching of higher education institutions [1]. The main reason why Case Teaching can be accepted by teachers and students is that, under the guidance of teachers, students can learn through Case Studies, combining theory with practice. Thus the Case Teaching not only enables students to quickly master the basic knowledge, but also enables students to combine theory with practice, and then apply what they have learned to real-life [2-3]. However, at present, for the teaching of Computer Programming Language, the existing teaching mode is mainly based on the teacher's lecture. The students complete the corresponding exercises, and the assessment is based on knowledge points, although the students can master the basic programming grammar well after the course rules, but can't comprehensively use the knowledge learned to analyze, design, code, and implement real-life problems [4-5]. For the students of senior computer-related majors, the traditional teaching mode can't meet the requirements of $\mathrm{C \#}$ programming language teaching. The main reasons are: (1) Through the lower grades, senior students mastered basic grammar rules for programming languages and object-oriented design ideas are still taught according to the structure of the textbooks[6-7]. Thus the efficiency of these students' learning is often low. (2) Senior students need to meet the requirements for applying job[8]. The traditional teaching methods obviously cannot meet the practical skills of IT companies. (3) Traditional teaching methods often only care about the $\mathrm{C \#}$ programming language itself, but rarely consider the effective integration of database, software architecture, software engineering, and other knowledge[9]. For senior college students, they are about to face employment. Their comprehensive application of knowledge is more important. Therefore, in the process of learning "C\# Programming Language", it is necessary to comprehensively apply Database, Network Programming, Software Architecture, Software Engineering, Object-oriented, and other knowledge to solve practical problems.

Although traditional teaching methods can solve the comprehensive application of related knowledge, for most students, the ability to solve practical work problems needs to be improved[10]. Therefore, more effective teaching methods are urgently needed to change the shortcomings of traditional teaching methods. To this end, this paper proposes a casebased teaching method of "C\# Programming Language". Firstly, it expounds on the design of basic cases and comprehensive cases. The basic cases are used to help students mastering basic knowledge[11]. The comprehensive case is used to help students conducting business analysis, system design, coding, and project implementation. In the implementation of the basic case, students are required to learn a few C\# basic cases, not only to master C\# basic knowledge but also to write a simple application. In the implementation of the comprehensive case, students are required to master the various stages of the ability about the research, requirements, design, coding, testing, implementation and so on, and can complete their practical projects[12]. According to the results of practical teaching from 2009 to 2016, Case Teaching can not only stimulate students to participate actively but also need teachers to guide actively. Thus they can achieve good teaching results and meet the needs of senior students for comprehensive learning of programming language.

\section{CASE DESIGN}

\section{A. Basic Case Design}

In the teaching process, to enable students to master the basic knowledge of the "C\# Programming Language", four basic cases were designed. (1) To help students master the basic knowledge of data types, variables, constants, operators, expressions, statements, functions, etc., the case of "24 point summation" was designed. (2) To enable students to master object-oriented packaging, inheritance, polymorphism, generics, collections and other knowledge, design a family farm case, this case is easy to understand, and combined with life practice. (3) To be able to display the results of the program friendly to the user, a simple notebook based on WinForm was designed. This case requires students to master 
the basic controls. (4) To enable students to better grasp the file processing, database creation, database table creation, database basic operations (insert, select, update, delete), a random pointto-device case was designed. At the same time, to facilitate the implementation of the basic case teaching, the number of class hours and the number of students in the case implementation are given here[13]. The basic requirements of the four basic cases used in the teaching process are shown in Table I.

TABLE I.

BASIC CASE

\begin{tabular}{|c|c|c|c|c|}
\hline Case name & Case description & Knowledge point & $\begin{array}{l}\text { Class } \\
\text { hour }\end{array}$ & People \\
\hline $\begin{array}{l}24 \text { point } \\
\text { summation }\end{array}$ & $\begin{array}{l}\text { Give four natural numbers arbitrarily between } 1 \text { and } 10 \text {, then use } \\
\text { addition, subtraction, multiplication and division to calculate, and } \\
\text { the result is } 24\end{array}$ & $\begin{array}{l}\text { The date types of C\# language, variables, constants, } \\
\text { operators, expressions, statements, functions }\end{array}$ & 8 & 1 \\
\hline Family farm & $\begin{array}{l}\text { Build a farm with a variety of animals: } \\
\text { Chicken, duck, goose, cow, super cow. }\end{array}$ & $\begin{array}{l}\text { Class integration in } \text { C\# language, } \\
\text { package,polymorphism, generics, collections }\end{array}$ & 8 & $1-2$ \\
\hline Simple notepad & Build a simple notepad for recording your usual work. & $\begin{array}{l}\text { Ability to use controls such as text, labels, } \\
\text { checkboxes, dialogs, etc. }\end{array}$ & 8 & $1-2$ \\
\hline $\begin{array}{l}\text { Random point } \\
\text { to the device }\end{array}$ & $\begin{array}{l}\text { Use the random point-to-pointer to make a point to the student, } \\
\text { each time } 5 \text { students, when the time is up, the student's basic } \\
\text { information can be displayed, including the avatar. }\end{array}$ & $\begin{array}{l}\text { For file processing, database creation, database } \\
\text { basic operations, understanding software three-tier } \\
\text { architecture }\end{array}$ & 8 & $1-2$ \\
\hline
\end{tabular}

As can be seen from Table I, the basic case gives the problem to be solved and the $\mathrm{C \#}$ foundation knowledge involved, as well as the number of people required to complete the basic case and participate in the case study, which the first basic case require the NO.1 group only have one person[14]. This reason is that the students need to master the basic concepts and related grammar knowledge at the beginning of the course. Other basic cases can be arranged for 2 people in one group or 1 person in one group. Different groups can explore each other.

\section{B. Comprehensive Case Design}

A well-designed and comprehensive case can not only examine students about the ability of C\# knowledge application but also comprehensively examine students' ability to comprehensively analyze and solve problems. However, if the same comprehensive case is used in the whole class, some students will be overcharged and not fully involved in the comprehensive case study. For this reason, according to the size of the class, design multiple cases with similar functions and certain differences in business. The basic business of these comprehensive cases is inconsistent, but the algorithms and processing methods can be the same, which can avoid the whole class to deal with a practical problem, and can facilitate the exchange of requirements, design, coding, testing, and implementation between groups. Table II gives four comprehensive cases used in the teaching process.

TABLE II. COMPREHENSIVE TEACHING CASE

\begin{tabular}{|c|c|c|c|c|}
\hline $\begin{array}{c}\text { Comprehensive case } \\
\text { name }\end{array}$ & Integrated case requirements & Knowledge point & $\begin{array}{l}\text { Class } \\
\text { hours }\end{array}$ & $\begin{array}{c}\text { Group } \\
\text { size }\end{array}$ \\
\hline $\begin{array}{l}\text { Blood pressure } \\
\text { monitoring } \\
\text { management }\end{array}$ & $\begin{array}{l}\text { Simulating the blood pressure data of } 10075 \text {-year-olds in their lifetime, it is } \\
\text { required to be able to master the basic operation of the database. The } \\
\text { probability of having hypertension over the age of } 50 \text { is } 60 \% \text {; it can display } \\
\text { the blood pressure data of any person in a curve; the displayed data can } \\
\text { reflecting blood pressure grading }\end{array}$ & $\begin{array}{l}\text { knowledge of blood pressure; } \\
\text { database, algorithm-based, } \\
\text { object-oriented knowledge; } \\
\text { vector, WinForm knowledge }\end{array}$ & 64 & 3-5 \\
\hline $\begin{array}{l}\text { Blood glucose } \\
\text { monitoring and } \\
\text { management }\end{array}$ & $\begin{array}{l}\text { Simulate blood glucose data of } 100 \text { people between the ages of } 30 \text { and } 80 \text {, } \\
\text { and the probability of having high blood sugar is } 10 \% \text {; it can display the } \\
\text { blood glucose data of each person's data monitored during their lifetime; } \\
\text { special treatment is needed for the critical value, when it is not displayed, it } \\
\text { needs filter the data. }\end{array}$ & $\begin{array}{l}\text { Basic knowledge of blood } \\
\text { glucose, } \\
\text { database knowledge, } \\
\text { algorithm related knowledge } \\
\text { object-oriented knowledge, } \\
\text { vector knowledge, } \\
\text { WinForm knowledge } \\
\end{array}$ & 64 & 3-5 \\
\hline $\begin{array}{l}\text { Blood lipid } \\
\text { monitoring and } \\
\text { management }\end{array}$ & $\begin{array}{l}\text { Simulate the blood lipid data of } 100 \text { people aged } 20 \text { to } 70 \text {, and can display } \\
\text { the data of each person's life in a curve. For special or critical values, special } \\
\text { processing is required, and scaling is required when displaying data. }\end{array}$ & $\begin{array}{l}\text { Blood lipid knowledge, database } \\
\text { knowledge, algorithm related } \\
\text { knowledge object-oriented } \\
\text { knowledge, vector knowledge, } \\
\text { WinForm knowledge }\end{array}$ & 64 & $3-5$ \\
\hline $\begin{array}{l}\text { Body temperature } \\
\text { monitoring } \\
\text { management }\end{array}$ & $\begin{array}{l}\text { Simulating the body temperature data of } 100 \text { people over the age of } 60 \text { can } \\
\text { display the body temperature data of each person in a curved way. The body } \\
\text { temperature of the critical point can be displayed in red, and a large amount } \\
\text { of body temperature data needs to be scaled. }\end{array}$ & $\begin{array}{l}\text { Body temperature changes, } \\
\text { database knowledge, algorithm } \\
\text { related knowledge } \\
\text { object-oriented knowledge, } \\
\text { vector knowledge, } \\
\text { WinForm knowledge }\end{array}$ & 64 & 3-5 \\
\hline
\end{tabular}

As can be seen from Table II, these four cases solve the actual business problems in four lives, and students in different groups need to have a good understanding of their respective businesses. For example, students in the body temperature group should understand the basic change of temperature of a person in their lifetime, and know the abnormal changes in body temperature when the body heat. Such students in the blood pressure group need a clear understanding of blood pressure grading. But the software architecture used in the four cases is consistent: data processing, business processing, and 
customer layers. The processing of these four basic cases is basically similar, which are based on the characteristics of the human body to make 100 people's life data, and then analyze the data, display the actual situation of the data according to the needs, and properly filter the data for reflecting the trend of data changes, so these four cases can meet the consistency of the software development process, the similarity of business processing, which greatly facilitates cooperation and communication within and between groups.

\section{CASE IMPLEMENTATION PROCESS}

To better implement the $\mathrm{C \#}$ case teaching method, the teaching process needs to carry out several important tasks: student mobilization before teaching, adequate preparation before the teacher, teacher's control of the case teaching process, and reasonable evaluation of case teaching. Student mobilization can greatly enhance the enthusiasm of students. For college undergraduates, the first case method is often difficult to accept, but for senior undergraduates, there is a certain programming foundation and a certain self-learning ability, so the implementation of case teaching is relatively easy. To make it easier for students to accept case teaching, some publicity is carried out before the students choose the class so that the students have a mental preparation[15]. In particular, the teacher is required to mobilize the students in the first class and explain the teaching process of the teaching plan so that the students can accept self-learning from the ideological perspective.

Before the case teaching, full preparation before the teacher's class is necessary. In addition to preparing the cases required for teaching, the instructors also need to prepare the following contents: (1)Fully prepare the teaching schedule and syllabus so that the teaching progress and teaching content can be more macroscopic observed; (2) Preparing the Case PowerPoint before implementing each case, the teacher needs to guide the students to analyze the method and key content of the case; (3) Set the key positions in the case, these places are easy for students to make mistakes, such as function coverage and function overloading in C\#; 4) Key location and class time for case discussions.

The case teaching process is to effectively control the case implementation. How to control the C\# case teaching needs to do the following: (1) In the previous two basic case teaching process, if the student does not master the relevant basic knowledge through case analysis, it is necessary to appropriately extend the learning time, If mastering the basic relative knowledge well, students can study the next case in advance; (2) In the process of learning the latter two basic cases, it has great similarity with other programming languages, and the senior undergraduates are also very easy to master. Therefore, the implementation time should be increased, and the discussion time should be reduced. (3) In the implementation of the comprehensive case, the guiding process should pay attention to firstly guide students to investigate and discuss the background of the project, such as blood pressure monitoring management: the current number of people with high blood pressure in our country is 260 million, blood pressure can be divided into 5 Level, the risk of blood pressure, the connection between blood pressure and living habits;(4) Teachers guide students to write requirements documents and design documents, which need to provide templates; (5) According to case analysis, students need to understand the organization of project coding and project engineering: configuration file processing classes, data processing classes, WinForm classes, startup classes, data filtering classes, curve processing class organization and scheduling; (6) packaging and deployment,although simple, effective deployment and implementation is the hallmark of the project's high-level: package and then install the project files, modify the configuration file, and deploy it on the test computer.

A reasonable grade assessment has great enthusiasm for students. The case teaching method adopts the written test method, which often fails to assess the students' comprehensive processing ability. For this reason, we use the method of case defense. Five cases were used throughout the teaching process, each of which accounted for $10 \%$ of the basic cases, and the comprehensive case accounted for $60 \%$ of the results. After each case, the students' grades were given. The final total score was the student's score, to make the assessment more reasonable, and teachers give the annotation of each case assessment. At the beginning of each case, the assessment content will be displayed to the students, so that the students can learn how to learn. The assessment content and the summary of the score are shown in Table III.

TABLE III. CONTENT AND STANDARDS OF THE CORRESPONDING CASES

\begin{tabular}{|c|c|c|c|}
\hline Case Name & Assessment requirements & Group size & Assessment score \\
\hline 24 point summation & $\begin{array}{l}\text { Ask questions about the given knowledge points: data types, constants, variable } \\
\text { operators and priorities, expressions, control statements, functions, and randomly } \\
\text { select matrix operations: add, subtract, and multiply to program. }\end{array}$ & 1 & $\begin{array}{l}\text { The answer to the } \\
\text { question is } 5 \text { points, } \\
\text { and the matrix is } 5 \text { points. }\end{array}$ \\
\hline Family Farm & $\begin{array}{l}\text { It can answer C\# inheritance, encapsulation, polymorphism and other related } \\
\text { issues. Construct a vector class: including the basic abstract graphics class, and } \\
\text { then require the design of lines, circles, rectangles, and convex polygons. The basic } \\
\text { properties include linear, line type, color, and line thickness. The basic methods } \\
\text { include drawing. }\end{array}$ & $1-2$ & $\begin{array}{l}\text { Can successfully answer } \\
\text { the question } 3 \text { points; } \\
\text { achieved programming } 7 \\
\text { points. }\end{array}$ \\
\hline Simple notepad & $\begin{array}{l}\text { Answer the application of common controls; design a simple calculator to achieve } \\
\text { simple addition, subtraction multiplication and division. }\end{array}$ & $1-2$ & $\begin{array}{l}\text { Answer } 2 \text { questions and } \\
\text { achieve } 8 \text { points. }\end{array}$ \\
\hline $\begin{array}{l}\text { Random point } \\
\text { to device }\end{array}$ & $\begin{array}{l}\text { Answer the basic meaning of the database } 2 \text { points; design a C\# grade management } \\
\text { system, requires the ability to check and sort. }\end{array}$ & $1-2$ & $\begin{array}{l}\text { Answer } 2 \text { questions and } \\
\text { achieve } 8 \text { points. }\end{array}$ \\
\hline Comprehensive case & $\begin{array}{l}\text { Imitate the comprehensive case given and construct a pulse rate monitoring system. } \\
\text { It is required to simulate the pulse rate data of } 100 \text { people over } 60 \text { years old and } \\
\text { collect } 3 \text { times of data every day. For abnormal values, it can be displayed } \\
\text { specially. }\end{array}$ & $2-3$ & $\begin{array}{l}10 \text { points for requirements, } \\
\text { design, and deployment; } \\
\text { code } 30 \text { points. }\end{array}$ \\
\hline
\end{tabular}


The case teaching assessment has certain subjectivity but basically can reflect the students' mastery of knowledge. Therefore, many people need to participate in the assessment process. The basic case assessment adopts the student recognition system and checks each other. The comprehensive case implementation assessment adopts a defense system. In addition to demonstrating what you have done, the defense process needs to give scores according to the clarity of the students' needs, design, coding, and deployment implementation process.

\section{ANALysis of CASE TEACHING EFFECTS}

From 2009 to 2016, the author has been the C\# Programming Language course for the third year of the School of Software. From 2009 to 2011, the traditional teaching method was adopted. From 2012 to 2016, the case teaching method was adopted. The project inspection method is adopted, that is, the comprehensive evaluation is based on the student's final project document and the project display result. The evaluation teacher is composed of three people, and the average value of the three teachers is taken as the final result.

First, the ratio of the number of students in each snippet from 2009 to 2016 is given, that is, the excellent rate (81-100), the good rate (70-80), the pass rate (60-70), and the fail rate (060). ), As shown in Fig. 1.

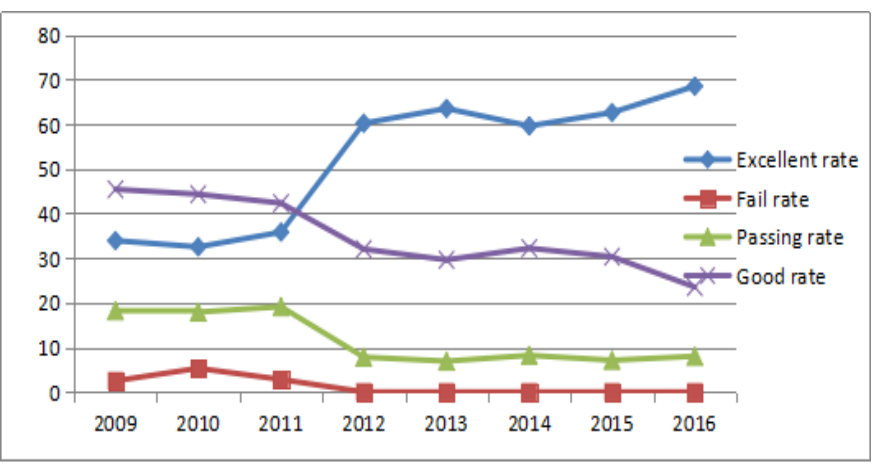

Fig. 1. The ratio of number of snipers from 2009 to 2016

It can be seen from Fig. 1 that after the case teaching method was adopted in 2012, the excellent rate increased significantly, and the number of people who failed to pass the case teaching method was 0 , and very few people from 60 to 70 scores. Most of the students are above 80 . When the traditional teaching method was adopted from 2009 to 2011, the excellent rate was below $40 \%$, and some students failed. It can be seen from the statistical results that the use of the Case Teaching method can improve students' interest in learning and improve their comprehensive ability.

Since 2012, 60 students have been surveyed each year, 30 of whom have participated in case teaching and 30 have not participated in case teaching. The questionnaire included 5 topics: (1) whether the initiative of learning increased; (2) whether the energy input was more; (3) whether it was difficult to integrate into IT enterprises; (4) whether it is timid to encounter actual problems that have not been touched;(5) Whether the ability to analyze problems and solve problems has improved. These five questions are judgment questions, and the statistical results are shown in Fig. 2. Among them, initiative, input, integration, timidity, and synthesis indicate that questions (1), (2), (3), (4), (5), where AL stands for case teaching and CT stands for traditional teaching.

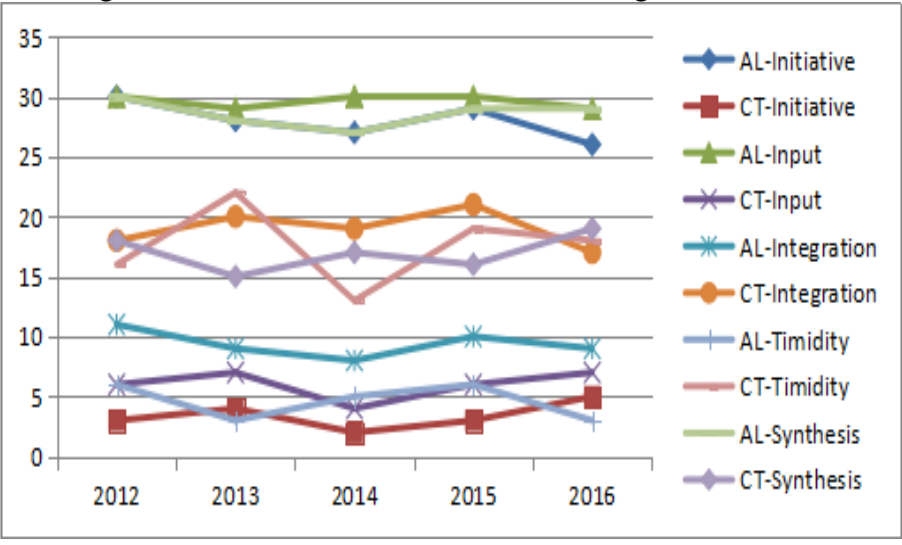

Fig. 2. Case Teaching and Traditional Teaching Questionnaire Results

As can be seen from Fig. 2, the survey results show that after the case teaching method, most students will not be timid when they encounter real-life problems, and they can analyze, design and code the problems according to the actual situation, Therefore, it can be well integrated into future work, but after using the case teaching method, students need to invest a lot of learning energy in the course.

\section{CONCLUSIONS}

In the senior undergraduate students of computer-related majors, it can be seen from the implementation of the case teaching of $\mathrm{C \#}$ programming language that case teaching requires students to participate actively, and teachers need to have a certain engineering project experience, which requires the strong support of the college. However, Case Teaching can enable students to quickly master the basic knowledge of C\# programming language and can improve students' ability to analyze and solve problems. More importantly, students can adapt to future work needs. This article was developed in the upper grades and achieved good results.

\section{ACKNOWLEDGMENT}

This work is supported by National Natural Science Foundation (No.61363075), and Science and Technology Department of Jiangxi Province (No.20161BBG70078), and Educational Office of Jiangxi Province (No. GJJ180270), and Special Scholarship for Visiting Scholars of Young and Middle-aged Teachers Development Programs in Regular Colleges in Jiangxi Province (Gan Education Office Letter [2016] No. 169).

\section{REFERENCES}

[1] Yu-QiaoMeng. Application of Theory and Practice Integration Teaching in $C$ Programming Language Course $[\mathrm{P}]$. Proceedings of the $3 \mathrm{~d}$ International Conference on Applied Social Science Research,2016. 
[2] Yu\&apos,e Song, Xiaofeng Chen, Chunhui Sun, Chengguo Wang. Teaching Research and Practice of Information Technology Course Based on Project Teaching Method[P]. Proceedings of the 3rd International Conference on Economics, Management, Law, and Education (EMLE 2017),2017.

[3] K. G. Prokofyev, O. V. Dmitrieva, T. R. Zmyzgova, E. N. Polyakova. Modern Engineering Education as a Key Element of Russian Technological Modernization in the Context of Digital Economy[P] Proceedings of the International Scientific Conference "Far East Con" (ISCFEC 2018),2019.

[4] Guiping Lu, Hao Wen, Weiqiang Mo, Ze Jin, Shan Lu, Xin Li. Research on the Teaching Reform of Electrotechnics in Robotics Engineering Based on IEET Engineering Education Certification[P]. Proceedings of the 2nd International Seminar on Education Research and Social Science (ISERSS 2019),2019.

[5] S. I. Osipova, N.V. Gafurova, V.V. Osipov. Development of Engineering Education According to the Demands of World Standards[P]. Proceedings of the International Scientific Conference "Far East Con" (ISCFEC 2018),2019.

[6] QingyuZou, Yan Liu. Teaching Exploration and Practice of Software Development Course Based on "Project Experience Learning Mode"[P] Proceedings of the 7th International Conference on Management, Education, Information and Control (MEICI 2017),2017.

[7] Hongmei Fan. Research on the Course of CNC Practice Based on Project Teaching at Application-Oriented College[P]. Proceedings of the 2nd International Conference on Social Science, Public Health and Education (SSPHE 2018),2019.

[8] Roby Lynn, Christopher Saldana, Thomas Kurfess, Nithin Reddy, Timothy Simpson, Kathryn Jablokow, Tommy Tucker, SaishTedia,
Christopher Williams. Toward Rapid Manufacturability Analysis Tools for Engineering Design Education[J]. Procedia Manufacturing,2016,5.

[9] Julian Kirchherr, Laura Piscicelli. Towards an Education for the Circular Economy (ECE): Five Teaching Principles and a Case Study[J]. Resources, Conservation \& Recycling,2019,150.

[10] Yao, Collins. Perspectives from graduate students on effective teaching methods: a case study from a Vietnamese Transnational University[J]. Journal of Further and Higher Education,2019,43(7).

[11] Jacobo Rodríguez, Ana Laverón-Simavilla, Juan M. delCura, José M. Ezquerro, Victoria Lapuerta, Marta Cordero-Gracia. Project-Based Learning experiences in space engineering education at the Technical University of Madrid[J]. Advances in Space Research,2015,56(7).

[12] AbdulhameedAlelaiwi, Abdullah Alghamdi, Mohammad Shorfuzzaman, MajdiRawashdeh, M. ShamimHossain, Ghulam Muhammad. Enhanced engineering education using smart class environment[J]. Computers in Human Behavior,2015,51.

[13] Roby Lynn, Christopher Saldana, Thomas Kurfess, Nithin Reddy, Timothy Simpson, Kathryn Jablokow, Tommy Tucker, SaishTedia, Christopher Williams. Toward Rapid Manufacturability Analysis Tools for Engineering Design Education[J]. Procedia Manufacturing,2016,5.

[14] Marcela Hernández-de-Menéndez, Antonio Vallejo Guevara, Juan Carlos TudónMartínez, Diana Hernández Alcántara, Ruben MoralesMenendez. Active learning in engineering education. A review of fundamentals, best practices, and experiences[J]. International Journal on Interactive Design and Manufacturing (IJIDeM),2019,13(3).

[15] Nam-Hwa Kang. A review of the effect of integrated STEM or STEAM (science, technology, engineering, arts, and mathematics) education in South Korea[J]. Asia-Pacific Science Education,2019,5(1).J. Clerk Maxwell, A Treatise on Electricity and Magnetism, 3rd ed., vol. 2. Oxford: Clarendon, 1892, pp.68-73. 